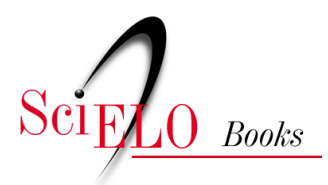

Parte II - Características e manifestações do modelo brasileiro: algumas reflexões

\title{
A inovação e o fortalecimento dos encadeamentos produtivos no desenvolvimento do Brasil
}

\author{
Aline Barbosa Dias Engelmann \\ Felipe Ghisleni Freitas
}

\section{SciELO Books / SciELO Livros / SciELO Libros}

ENGELMANN, A.B.D., and FREITAS, F.G. A inovação e o fortalecimento dos encadeamentos produtivos no desenvolvimento do Brasil. In: ROTTA, E., LOPES, H. C., and ROSSINI, N., eds. O modelo de desenvolvimento brasileiro das primeiras décadas do século XXI: aportes para o debate [online]. Chapecó: Editora UFFS, 2018, pp. 246-254. ISBN: 978-85-64905-82-5. https://doi.org/10.7476/9788564905832.0011.

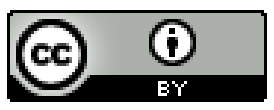

All the contents of this work, except where otherwise noted, is licensed under a Creative Commons Attribution 4.0 International license.

Todo o conteúdo deste trabalho, exceto quando houver ressalva, é publicado sob a licença Creative Commons Atribição 4.0.

Todo el contenido de esta obra, excepto donde se indique lo contrario, está bajo licencia de la licencia Creative Commons Reconocimento 4.0. 
PARTE II

CARACTERÍSTICAS E MANIFESTAÇÕES DO MODELO BRASILEIRO

- ALGUMIAS REFLEXÕES 


\title{
A INOVAÇÃO E O FORTALECIMENTO DOS ENCADEAMENTOS PRODUTIVOS NO DESENVOLVIMENTO DO BRASIL
}

\author{
Aline Barbosa Dias Engelmann \\ Felipe Ghisleni Freitas
}

\section{INTRODUÇÃO}

O desenvolvimento histórico das forças produtivas tem resultado em uma capacidade sempre crescente de as sociedades produzirem excedentes sociais cada vez maiores (HUNT, 2013). Inúmeras vezes desenvolver-se é adequar o que se tem de melhor e utilizar potencializadores para promover uma melhor expansão, proporcionando acréscimo na economia.

Segundo Bresser-Pereira (2006, p. 1), o desenvolvimento econômico tende a ser automático na medida que, no sistema capitalista, o mercado envolve incentivos para o aumento do capital e desenvolvimento dos conhecimentos técnicos.

Para Bielschowsky (2014), o Brasil possui três frentes de expansão importantes: um grande mercado interno de consumo de massa, abundantes recursos naturais e perspectivas favoráveis quanto à infraestrutura. E essas frentes de expansão serão melhores utilizadas se forem potencializadas com a inovação e o fortalecimento dos encadeamentos produtivos.

O desenvolvimento é, portanto, um fenômeno relacionado com o surgimento das duas instituições fundamentais do novo sistema capitalista: 
o estado e os mercados (BRESSER-PEREIRA, 2006). Logo, a inovação e o fortalecimento dos encadeamentos produtivos vêm para fortalecer as três frentes e auxiliar essas instituições fundamentais do sistema capitalista.

Tigre (2006, p. 13) define que a inovação tecnológica constitui uma ferramenta essencial para aumentar a produtividade das organizações, assim como para impulsionar o desenvolvimento econômico de regiões e países. Quanto ao restabelecimento de encadeamentos produtivos, o autor ainda afirma que é preciso fazer uma pesquisa fundamentada na matriz de insumo-produto, identificando as ligações das cadeias produtivas clássicas que enfraqueceram ou se perderam, bem como as que ainda têm um potencial de competitividade estabelecido.

Nesse contexto, a inovação e o fortalecimento dos encadeamentos produtivos se tornaram o tema central deste capítulo, que busca verificar o referencial teórico em torno do tema para sua melhor compreensão. Assim, esta pesquisa se restringe a uma pesquisa bibliográfica dos principais conceitos, partindo do pressuposto de que o desenvolvimento nacional precisa ser alicerçado em pilares de sustentação, como a inovação e os encadeamentos produtivos.

\section{A INOVAÇÃO E O DESENVOLVIMENTO BRASILEIRO}

O desenvolvimentismo é o sistema de ideias que transformam a sociedade e tem alguns tópicos principais: a indústria como maneira de combater a pobreza; a industrialização efetiva através da intervenção do estado, em que o Estado deve também planejar, definir, ampliar, ordenar e executar o desenvolvimento (BIELSCHOWSKY, 2014).

$\mathrm{O}$ conceito de desenvolvimento tem ganhado algumas modificações em seu conteúdo nos últimos quarenta anos; inicialmente, esse termo denotava fenômenos estritamente econômicos, como o aumento da renda per capita; a partir de 1970, foram inseridos ao termo outros nomes, como 
desenvolvimento sustentável ou desenvolvimento humano (PINHEIRO, 1990).

O desenvolvimento não deriva de um mero crescimento das atividades econômicas existentes, "mas reside em um processo qualitativo de transformação da estrutura produtiva no sentido de incorporar novos produtos e processos e agregar valor à produção por meio da intensificação do uso da informação e do conhecimento" (TIGRE, 2006, p. 13). É o que ocorre, segundo o mesmo autor, com vários países que estão conseguindo superar o subdesenvolvimento com investimentos em educação e tecnologia e também com a entrada bem-sucedida em setores mais inovadores e dinâmicos da economia mundial.

Tigre (2006, p. 13) entende ainda que:

O desenvolvimento depende essencialmente de transformações que gerem empregos, criem novas formas de organização, atendam a novas necessidades dos consumidores e melhorem a própria forma de viver. [...] Uma vez iniciado, o desenvolvimento econômico tende a ser relativamente automático ou autossustentado na medida em que no sistema capitalista os mecanismos de mercado envolvem incentivos para o continuado aumento do estoque de capital e de conhecimentos técnicos.

Todavia, para que haja desenvolvimento é preciso que as instituições assegurem a ordem pública, o adequado funcionamento do mercado e um mercado que gere boas oportunidades para que os empresários possam e queiram investir e inovar (BRESSER-PEREIRA, 2006).

Nesse sentido, conforme Garcia e Madeira (2012, p. 22), "estes processos acarretam o aumento da produtividade das empresas e do sistema como um todo, além de ganhos obtidos na esfera organizacional, com isso, as economias externas são geradas e intensificadas". E as inovações nos diferentes setores da economia seguem trajetórias tecnológicas distintas, que consistem em possíveis direções do desenvolvimento. 
A inovação é, sem dúvida, um grande incentivo em larga escala, tanto para o desenvolvimento de organizações privadas quanto para impulsionar o desenvolvimento dos países. Para Pacheco (2010, p. 6),

Inovação é hoje uma parte importante da agenda pública e privada em praticamente todos os países industrializados ou nas economias emergentes. Seja como parte das políticas industriais ou com uma roupagem ainda mais ampla que essa, as políticas de apoio à inovação estão no cerne das ações de apoio à competitividade e à criação de melhores empregos.

Para Guimarães (2010, p. 20), ao Estado cabe o papel de coordenação e regulação, que pode ser exercido através de financiamentos e incentivos, e pode agir para atender a sua própria demanda ou à demanda de setores que prioriza, no quadro de uma política de desenvolvimento.

É por isso que "à medida que cresce a influência de tais ideias, a agenda governamental passa a incorporar a temática na forma de políticas públicas voltadas para reduzir o atraso tecnológico" (LACERDA, 2015, p. 2).

Não obstante, o processo de desenvolvimento também acontece em um plano macro, fundamentado em interações microeconômicas ocorrentes no interior de firmas, por meio de inovações e aperfeiçoamentos de rotinas, levando-as a uma melhor posição de mercado. Esse desenvolvimento é altamente influenciado pela cultura das pessoas e ou sociedade que estão ligadas ao desenvolvimento e proporcionam a inovação e o crescimento técnico através de incentivos.

Pode-se dizer que existe um processo de intercâmbio entre empresas e formas institucionais, pois enquanto as firmas se adaptam a regulações institucionais, desenvolvem comportamentos que modificam suas características. Assim, quando da inexistência ou insuficiência de inovações socioinstitucionais, o ritmo de crescimento da esfera produtiva é diretamente afetado negativamente (LOPES, 2013). 
Portanto, evolução técnica e sua disseminação podem ser oriundas da inovação que ocorreu no interior das firmas, em paralelo com a revolução tecnológica e o padrão tecno-econômico em andamento, fundamentados nas rotinas mentais dos agentes que podem variar ou permanecer estáticos conforme as ocorrências. Essas novas formas estão submetidas a um método de escolha e adequação às condições socioeconômicas vigorantes, propiciam resultados expressivos de produtividade e invadem a sociedade, proporcionando melhores condições para a população.

\section{FORTALECIMENTO DOS ENCADEAMENTOS PRODUTIVOS}

O conceito de cadeia produtiva tem sido um dos temas de grande importância nas últimas décadas. Seu estudo permite a compreensão dos impactos que as ações internas e externas podem causar, assim como identificar as oportunidades e potencialidades (ZANELLA et al., 2016, p. 63).

Nesse sentido,

A contribuição de um setor para o crescimento da economia não se restringe ao seu próprio desempenho. Sua capacidade dinamizadora depende de seu poder de encadeamento produtivo. [...] setores com elevado efeito multiplicador ao longo da cadeia produtiva podem aquecer a demanda por outros bens, caso os efeitos para trás sejam importantes, e/ou podem contribuir para o crescimento da economia fornecendo insumos para diversos outros setores, caso os efeitos "para frente" (CASTILHO, 2011, p. 41).

Segundo Bielschowsky (2014), fortalecer os encadeamentos produtivos é tão importante quanto reestruturar aqueles que por algum motivo foram danificados. Há ainda necessidade de identificar os gargalos da ineficiência dessas cadeias produtivas, sendo importante verificar as políticas 
públicas e tecnológicas para a capacitação dos encadeamentos produtivos (VIEIRA et al., 2001).

Segundo Chenery et al. (1986), a maior parte da demanda por produtos manufaturados são oriundas do próprio setor, assim encadeamentos produtivos são relevantes para diversificação na produção de bens intermediários. Logo, a cadeia de valor de um bem acaba sendo formada com a produção de bens intermediários, por meio de outros bens intermediários, o que se justifica pelo fato de não existir em sua totalidade uma relação direta entre um bem primário e o bem final.

Chenery et al. (1986) vão além em sua contribuição, ao afirmar que o aumento da renda per capita sofre influência direta da produção de bens intermediários, que necessitam de uma combinação de insumos no processo produtivo, e por setores como o agrícola, que utilizam uma gama significativa de produtos manufaturados.

Em contraponto, Magacho (2010) afirma que o enfraquecimento de encadeamentos produtivos afeta a habilidade natural da indústria em produzir internamente meios para o crescimento. Assim, a indústria dependeria cada vez mais dos mercados externos, através do comércio exterior, de investimento estatal em infraestrutura e incentivo ao consumo.

Segundo Marconi (2011), a dependência de mercados externos levaria à substituição da oferta de insumos nacionais por estrangeiros, o que poderia afetar diretamente o encadeamento produtivo, visto que a produção de um único bem pode representar somente que o produto final seja a montagem de componentes importados em sua totalidade, levando a indústria a fabricar produtos com menor valor agregado, oriundos de uma indústria de montagem.

No Brasil, a exportação de bens primários, sem muita tecnologia agregada, ainda ocupa papel importante na cadeia de valor. Embora exista um vasto campo comercial de produtos transformados a partir de minerais, pedras preciosas e produtos naturais ou industrializados a partir de alimentos e seus derivados, o Brasil não aproveita em sua plenitude seu potencial, 
como fazem países já industrializados como o Japão, que fatura muito na indústria de joias com base no ouro, diamantes e outras pedras preciosas contrabandeadas ou compradas do próprio Brasil e de países da África.

Com uma reestruturação produtiva e o dinamismo das inovações tecnológicas nos tempos atuais, as demandas de tecnologia por parte dos componentes da cadeia podem apresentar sinergia, neutralidade ou conflitos, por esta razão que os centros de $\mathrm{P} \& \mathrm{D}$ consideram importante o exame completo da cadeia produtiva, ponderando as demandas de todos os seus componentes na definição da estratégia tecnológica a ser adotada (SIMIONI et al., 2007).

\section{CONSIDERAÇÕES FINAIS}

De maneira pontual, observa-se que a inovação vem sendo em larga escala propulsora de desenvolvimento em vários setores dos países. Inovar é buscar novas alternativas para modificar o cenário existente, seja em produtos ou processos, ou como já mencionado, no desenvolvimento dos países.

Segundo os autores mencionados neste capítulo, o desenvolvimento é um conjunto de transformações que acarretam modificações na estrutura dos países, com o emprego de novas tecnologias, melhorando a produção, a renda, a inserção do país no mercado internacional.

Outro fator importante que foi diagnosticado é o fortalecimento dos encadeamentos produtivos e também a recuperação daqueles que estão fragilizados; nesse sentido, é preciso intervenção do governo quanto a políticas que auxiliem o fortalecimento dessas cadeias, que, por sua vez, perderam a competitividade e força para atuar no mercado globalizado. Todavia, não perderam sua importância para o desenvolvimento do Brasil.

Esses dois fatores, se bem aproveitados, poderão propiciar desenvolvimento para o país, porém é preciso que exista um adequado planejamento das políticas de desenvolvimento do país, para que os fatores possam ser eficientes em todos os setores da economia. 


\section{REFERÊNCIAS}

BIELSCHOWSKY, R. Presente e futuro do desenvolvimento brasileiro. CALIXTRE, A. B.; BIANCARELLI, A. M.; CINTRA, M. A. M. (Ed.). Brasília: IPEA, 2014.

BRESSER-PEREIRA. L, C. O conceito histórico de desenvolvimento econômico. Texto para discussão $157 \mathrm{EESP/FGV,} \mathrm{2006.} \mathrm{Disponível} \mathrm{em:} \mathrm{<http://}$ www.bresserpereira.org.br/view.asp? cod=1726>. Acesso em: 25 maio 2016.

CASTILHO, R. M. Encadeamentos produtivos das atividades exportadoras na América Latina: o caso dos setores industriais no Brasil. 2011. Disponível em: <http://www19.iadb.org/intal/intalcdi/PE/2011/08672.pdf>. Acesso em: 28 maio 2016.

CHENERY, H.; SHERMAN, R.; MOSHE, S. Industrialization and growth. Oxford University Press, published for the World Bank, 1986. Disponível em: <http://citeseerx.ist.psu.edu/viewdoc/ download?doi=10.1.1.466.9761\&rep=rep1\&type=pdf $>$. Acesso em: 20 jun. 2016.

GARCIA, R.; MADEIRA, P. Uma avaliação da difusão de práticas de gestão da produção entre pequenas empresas em sistemaslocais de produção. Production, São Paulo, v. 23, n. 1, p. 20-30, jan./mar. 2013. Disponível em: <http://www. scielo.br/scielo.php?script=sci_arttext\&pid=S0103-65132013000100002\&lng $=$ pt\&nrm=iso $>$. Acesso em: 18 mar. 2016.

GUIMARÃES, T. de J. Instituições e empresas no processo de geração de inovações: um estudo de caso da Natura. 2010. Dissertação (Mestrado em Políticas Públicas) Instituto de Economia da Universidade Federal do Rio de Janeiro, Rio de Janeiro, 2010. Disponível em: <http://www.ie.ufrj.br/images/ posgraducao/pped/defesas/14-terezinha_de_Jesus_Guimares.pdf>. Acesso em: 23 jun. 2016.

HUNT, E, K; LAUTZENHEISER, M. História do pensamento econômico. Rio de Janeiro: Elsevier, 2013.

LACERDA, N. et al. Parques tecnológicos: entre inovação e renda imobiliária no contexto da cidade do Recife. Caderno Metropolitano, São Paulo, v. 17, n. 34, nov. 2015. Disponível em: <http://dx.doi.org/10.1590/2236-9996.20153402>. Acesso em: 17 abr. 2016.

LOPES, H. C. Instituições e crescimento econômico: os modelos teóricos de Thorstein Veblen e Douglass North. Revista de Economia Política, v. 33, n. 4, p. 619-637, 2013. 
MAGACHO, G. R. Desarticulação das Cadeias Produtivas no Brasil: Impacto sobre a Geração de Emprego e a Renda (1995-2008). Boletim NEIT - Núcleo de Economia Industrial e da Tecnologia, n. 15, jan./abr. 2010. Disponível em: $<$ https://www3.eco.unicamp.br/neit/images/stories/arquivos/BoletimNeit/ Boletim-NEIT_151.pdf >. Acesso em: 15 abr. 2016.

MARCONI, N.; ROCHA, M. Desindustrialização precoce e sobrevalorização da taxa de câmbio. Texto para discussão n. 1681, IPEA, 2011. Disponível em: <http://www.ipea.gov.br/portal/images/stories/PDFs/TDs/td_1681.pdf>. Acesso em: 15 jun. 2016.

PACHECO, C. A. Desafios da inovação. Incentivos para inovação: o que falta ao Brasil. [S.l.]: IEDI, 2010. Disponível em: <http://www.iedi.org.br/ admin_ori/pdf/20100211_inovacao.pdf>. Acesso em: 21 maio 2016.

PINHEIRO, M.M.S. Asliberdades humanas como bases dodesenvolvimento: uma análise conceitual da abordagem das capacidades humanas de Amartya Sen. Brasília: Rio de Janeiro: IPEA, 1990. Disponível em: <http://www.ipea. gov.br/portal/images/stories/PDFs/TDs/td_1794.pdf>. Acesso em: 9 abr. 2016.

SIMIONI, F. J. Análise diagnóstica e prospectiva de cadeias produtivas:uma abordagem estratégica para o desenvolvimento. In: XLV Congresso da Sociedade Brasileira de Economia, Administração e Sociologia Rural, 2007, Londrina. Disponível em: <http://www.sober.org.br/palestra/6/800>. Acesso em: 21 jun. 2016.

TIGRE, P. B. Gestão da inovação: a economia da tecnologia do Brasil. Rio de Janeiro: Elsevier, 2006.

VIEIRA, R. de C. M. T. et al. (Ed.). Cadeias Produtivas no Brasil: Análise da Competitividade. Brasília: EMPRAPA, 2001. Disponível em: <http:// livimagens.sct.embrapa.br/amostras/00075020.pdf>. Acesso em: 28 jun. 2016.

ZANELLA, C. et al. Competitividade em cadeias produtivas: uma análise bibliométrica a partir dos periódicos CAPES. Qualitas, Paraíba, v. 17, n. 1, jan./mar. 2016. Disponível em: <http://dx.doi.org/10.18391/ req.v17i1.2587>. Acesso em: 28 jun. 2016. 